\title{
Therapeutic Potential of Human Mesenchymal Stromal Cells Secretome
}

\author{
Luigi Balducci ${ }^{*}$ and Gianluca Accogli² \\ ${ }^{1}$ Laboratory of Cell Culture and Molecular Biology, CARSO Consortium, Valenzano, Bari, Italy \\ ${ }^{2}$ Veterinary Clinics and Animal Productions Unit, Department of Emergency and Organ transplantation (DETO), University of Bari "Aldo Moro", Bari, Italy
}

Human multipotent mesenchymal stromal cells (hMSCs) have been isolated and expanded from several tissues. Bone marrow [1], adipose tissue [2], umbilical cord [3], skeletal muscle [4] and skin [5] are only a small example of hMSCs origin. Due to the heterogeneity deriving from the different cell source and isolation methods, three minimal criteria have been proposed to define hMSCs: plasticadherence, phenotypic profile (positive expression of CD105, CD73 and CD90 and lack expression of CD45, CD34 and HLA-II), and trilineage mesenchymal differentiation potential [6]. From a functional point of view, many in vitro and in vivo studies have showed that hMSCs possess immune-modulatory, pro-angiogenic, pro-survival, anti-apoptotic, anti-oxidant, anti-fibrotic, anti-bacterial and neuroprotective properties. As a consequence, hMSCs have become a very interesting tool for cell therapy and regenerative medicine, and they still continue to be studied for this purpose.

Several findings have elucidated that hMSCs release a plethora of cytokines, interleukins, prostaglandins and growth factors. More recently, it has also been demonstrated that hMSCs secrete exosomes and microvesicles $[7,8]$. The main differences between these subcellular particles are essentially their size (40 to $100 \mathrm{~nm}$ for exosomes and 100 to $1000 \mathrm{~nm}$ for microvesicles) and origin (exosomes by exocytosis of multivesicular bodies, microvesicles by budding of plasma membranes). In contrast, the common feature of both particles is their content, consisting of proteins, lipids, mRNAs, and microRNAs (miRNAs) [9]. All together, the above mentioned factors and the subcellular particles containing the active bio-molecules represent the hMSCs secretome.

Many studies have ascertained and still continue to clarify that the hMSCs therapeutic potential is linked to their secretory abilities. Skin aging [10], myocardial ischemia/reperfusion injury [11], stroke [12], and wound healing [13] are representative examples of pre-clinical investigations evaluating the effectiveness of hMSCs secretome. Of note, also some clinical studies have been conducted to assess the regenerative properties of hMSCs secretome $[14,15]$.

Compared to direct hMSCs administration, the employment of cell secretome for therapeutic scopes could have at least three advantages. The first benefit relates to the possibility to avoid potential problems such as tumorigenicity, pathogens transfer and donor-recipient mismatch when cells are administered. From a practical point of view, the hMSCs secretome could be managed and manufactured in an easier way compared to cell suspensions, specifically in terms of storage, availability, delivery and quality testing. Moreover, such biological material may represent a ready-to-use therapeutic device, particularly important when used for acute pathologies where the time required to expand cells could be unfavorable.

Undoubtedly, several concerns about hMSCs secretome as a therapeutic tool remain to be solved. Thus, future challenges should address fundamental aspects regarding the production, safety, and characterization of hMSCs secretome. The first point principally aims to manufacture large quantities (scale-up) of hMSCs secretome in accordance to GMP-procedures. We have recently proposed a possible strategy to obtain large amounts of hMSCs secretome [16]. However, it is mandatory to analyze more extensively this hypothesis by performing in vitro and in vivo studies.

The second aspect is particularly urgent in order to avoid detrimental side effects deriving from hMSCs secretome administration. Indeed, it was recently reported that exosomes could be involved in cancer and neurodegenerative disorders $[17,18]$.

Finally, a deeper molecular characterization would allow a better definition of the hMSCs secretome content. New methodologies such as NGS (Next Generation Sequencing) and glycome-profiling will be very valuable to understand the molecular composition and the related functions of the hMSCs secretome biomolecules and subcellular particles.

In conclusion, the characterization and therapeutic application of hMSCs secretome may represent a new and exciting field of research for the scientific community.

\section{References}

1. Friedenstein AJ, Petrakova KV, Kurolesova AI, Frolova GP (1968) Heterotopic of bone marrow. Analysis of precursor cells for osteogenic and hematopoietic tissue. Transplantation 6: 230-247.

2. Kirkland JL, Hollenberg CH, Gillon WS (1993) Two preadipocyte subtypes cloned from human omental fat. Obes Res 1: 87-91.

3. Bieback K, Kern S, Kluter H, Eichler H (2004) Critical parameters for the isolation of mesenchymal stem cells from umbilical cord blood. Stem Cells 22 625-634.

4. Alessandri G, Pagano S, Bez A, Benetti A, Pozzi S, et al (2004) Isolation and culture of human muscle-derived stem cells able to differentiate into myogenic and neurogenic cell lineages. Lancet 364: 1872-1883.

5. Toma JG, McKenzie IA, Bagli D, Miller FD (2005) Isolation and characterization of multipotent skin-derived precursors from human skin. Stem Cells 23: $727-$ 737.

6. Dominici M, Le Blanc K, Mueller I, Slaper-Cortenbach I, Marini F, et al. (2006) Minimal criteria for defining multipotent mesenchymal stromal cells. The International Society for Cellular Therapy position statement. Cytotherapy 8 : 315-317.

7. Lai RC, Arslan F, Lee MM, Sze NS, Choo A, et al. (2010) Exosome secreted by MSC reduces myocardial ischemia/reperfusion injury. Stem Cell Res 4: 214222

8. Gatti S, Bruno S, Deregibus MC, Sordi A, Cantaluppi V, et al. (2011) Microvesicles derived from human adult mesenchymal stem cells protect against ischaemia-reperfusion-induced acute and chronic kidney injury. Nephrol Dial Transplant 26: 1474-1483.

*Corresponding author: Luigi Balducci, Laboratory of Cell Culture and Molecula Biology, CARSO Consortium, Strada Prov.le Valenzano-Casamassima km.3, 70010 Valenzano, Bari, Italy, Tel: +39-080-4602121; E-mail: luigi.balducci.lb@gmail.com

Received January 25, 2016; Accepted January 27, 2016; Published February 01, 2016

Citation: Balducci L, Accogli G (2016) Therapeutic Potential of Human Mesenchymal Stromal Cells Secretome. J Biomol Res Ther 5: e144. doil10.4172/2167. 7956.1000e144

Copyright: $\odot 2016$ Balducci L, et al. This is an open-access article distributed under the terms of the Creative Commons Attribution License, which permits unrestricted use, distribution, and reproduction in any medium, provided the original author and source are credited. 
Citation: Balducci L, Accogli G (2016) Therapeutic Potential of Human Mesenchymal Stromal Cells Secretome. J Biomol Res Ther 5: e144. doi:10.4172/2167-7956.1000e144

Page 2 of 2

9. Konala VB, Mamidi MK, Bhonde R, Das AK, Pochampally R, et al. (2016) The current landscape of the mesenchymal stromal cell secretome: A new paradigm for cell-free regeneration. Cytotherapy 18: 13-24.

10. Park BS, Jang KA, Sung JH, Park BS, Kwon YH, et al. (2008) Adipose-derived stem cells and their secretory factors as promising therapy for skin aging. Dermatol Surg 34:1323-1326.

11. Arslan F, Lai RC, Smeets MB, Akeroyd L, Choo A, et al. (2013) Mesenchymal stem cell-derived exosomes increase ATP levels, decrease oxidative stress and activate $\mathrm{PI} 3 \mathrm{~K} / \mathrm{Akt}$ pathway to enhance myocardial viability and prevent adverse remodeling after myocardial ischemia/reperfusion injury. Stem Cell Res 10: 301-312

12. van Velthoven CT, Kavelaars A, Heijen CJ (2012) Mesenchymal stem cells as a treatment for neonatal ischemic brain damage. Pediatric Res 71: 474-481.

13. Li M, Luan F, Zhao Y, Hao H, Liu J, et al. (2015) Mesenchymal stem cellconditioned medium accelerates wound healing with fewer scars. Int Wound J.
14. Fukuoka $\mathrm{H}$, Suga $\mathrm{H}$ (2015) Hair regeneration treatment using Adipose-derived stem cell conditioned medium: Follow-up with trichograms. Eplasty 15: e10.

15. Katagiri W, Osugi M, Kawai T, Hibi H (2016) First-in-human study and clinical case reports of the alveolar bone regeneration with secretome from human mesenchymal stem cells. Head Face Med 12: 5.

16. Balducci L, Saldarelli M, Alessandri G (2015) Immortalization of human adiposederived stem cells as useful tool to produce cell-secreted paracrine factors for future applications in cell therapy and regenerative medicine. Insights in Stem cells 1: 1 .

17. Salido-Guadarrama I, Romero-Cordoba S, Peralta-Zaragoza O, HidalgoMiranda A, Rodríguez-Dorantes M (2014) MicroRNAs transported by exosomes in body fluids as mediators of intercellular communication in cancer Onco Targets Ther 7: 1327-1338.

18. Bellingham SA, Guo BB, Coleman BM, Hill AF (2012) Exosomes: vehicles fo the transfer of toxic proteins associated with neurodegenerative diseases? Front Physiol 3: 124. 